THURSDAY, APRIL 16, 1874

\section{THE ADAPTATION OF OUR UNIVERSITIES TO THE WANTS OF THE AGE}

$\mathrm{T}^{\mathrm{T}}$ has given us special pleasure during the last few 1 years to record the efforts made in several of our British Universities and Colleges to adapt their teaching and their appliances for teaching to the present state of knowledge. We have seen what has been done by means of a fraction of the splendid revenues of Oxford, what the princely munificence of her Chancellor is providing for Cambridge, and what public subscriptions aided by judicious liberality on the part of Government have enabled Glasgow to achieve. Let us see what is now being attempted by a University which, though for its years rich in usefulness and fame, even relatively to those just mentioned, is, so far as funds are concerned, in a state approaching to indigence.

A short paragraph in our last number called the attention of our readers to the important step which has just been taken by the University of Edinburgh, with the view of thoroughly adapting its lecture-rooms and laboratories at once to the enormously increased numbers of its teachers and students, and to the ever-growing demands of physical and biological science.

Increase of numbers of teachers and taught would of itself demand a proportionate increase of space, which in Edinburgh must be considerably more than two to one as regards lecture-rooms alone. But when we consider the improvements which have been introduced into the modes of teaching, the imperative necessity for practical instruction in addition to lectures and demonstrations; nay more, the desirability of enabling (professors not merely to teach what is known, but also, by original research conducted by themselves, and their more promising students, to endeavour to extend the boundaries of Science : we see how immense are the issues involved in the step which Edinburgh has just taken.

That it will be successful, no one who knows Scotland and Scotsmen can for a moment doubt. But Scotland is a comparatively poor country-receiving back from the Treasury a much smaller fraction of her taxation than more favoured portions of the empire-and Edinburgh University is, relatively to the number of her students, by far the poorest of even the poor Scottish Universities. It is to be hoped, therefore, that Government aid will be forthcoming, as in the recent case of Glasgow, to eke out the efforts of those who, with as good a cause as could be wished for, and hearty desire to advance it, yet cannot entirely rely on the results of their unaided exertions. All former Edinburgh alumni, scattered as they are broadcast over the world, especially in England and in India, must be prepared to acknowledge, by such contributions as they can afford to make, the value of the instruction they have received. Let no one abstain from giving because of the smallness of the sum he can afford; every mite is of importance-let him rather rejoice that he has the opportunity, which appears to occur but once in a century, of contributing to so noble an object.

The story of her last successful endeavour to meet wants to a certain extent akin to those now felt is well told in the following extract from the Programme of the Acting Committee :-

"One hundred years ago, an Appeal was made to the public on behalf of the University of Edinburgh. The number of students was then stated as 'betwixt six and seven hundred,' the inadequacy of the collegiate buildings to the size and importance of the University was pointed out, and it was declared that while in Edinburgh great improvements were going forward on all hands, 'the University fabric alone' remained 'in such a neglected state, as to be generally counted a dishonour to the City of Edinburgh, and to this part of the kingdom.'

"The result of that Appeal was a liberal public subscription, opened in March 1768, which, with the aid of Government, provided the handsome edifice now existing. That building for a long period amply sufficed for all the teaching purposes of the University. But the lapse of a century has produced great changes. During that period the population of the metropolis has been more than trebled ; increased facilities for travelling have brought the University within easy reach of all parts of the country ; the advantages of a University education have become much more appreciated; the advancement of Science has widely extended the field of academic teaching ; and the renown alike of teachers and graduates, whose names will ever be associated with the University of Edinburgh, has increased its fame and reputation throughout the world.

"Thus, the buildings of the University again prove to be wholly inadequate to its necessities. This inadequacy is felt in various ways.

"The number of students attending the University in I768 was 'betwixt six and seven hundred,' and the number of Professors was 2I. In the present Session $(1873-4)$ the number of students is between 1,900 and 2,000, and that of the Professors is 35. The Classroom accommodation has thus become wholly insufficient. The students at present attending the Chemistry, Anatomy, and Natural History Classes number about 300 in each case. The Lecture-rooms are consequently much overcrowded, and great personal discomfort is thus occasioned to both the teachers and the taught.

"But apart from the present buildings being insufficient as regards the students in attendance, the nature of the modern system of teaching in several branches has rendered the existing accommodation altogether unsuitable.

"Since the present University buildings were erected, the whole subject of Practical Chemistry has been added to the course of study. Within the last ten years large and commodious laboratories have been provided in connection with many of the European Universities, and it would be most unfortunate if the University of Edinburgh, which was the first British school to introduce practical instruction in Chemistry into the medical curriculum, were not enabled to carry on satisfactorily this important branch of medical and scientific training.

"Again, the instruction formerly given in Anatomy consisted almost entirely of lectures and demonstrations delivered in the class-room. The changes in Medical education during the last thirty years render it necessary that each student should now pursue for himself the study of Practical Anatomy. The rooms at present in use were not constructed for that purpose, and are lamentably inadequate for the work to be done in them.

"But besides the departments of Chemistry and Anatomy, increased accommodation, in the form of Laboratories, and rooms suited for microscopic and other practical investigation and instruction, is required for the Chairs of Materia Medica, the Institutes of Medicine, Natural History, and Pathology. Nor is it less urgent that much additional accommodation for the apparatus and the Physical Laboratory of the Chair of Natural Philosophy should be provided." 
Take these in turn-the last-mentioned first. The Physical Laboratory has been but six years in existence ; simply because it was impossible sooner to find any accommodation for it. One small room was obtained capable of holding a dozen students (at very high pressure). The success of the first year was so great that in the next session more than half of the applicants had to be refused admission; and as the demand grew, the working time allowed each student per day had to be further and further restricted, till, in the session just concluded, the lowest admissible limit (one hour per day) had at first to be adopted, and yet several applications for admission had to be refused. In spite of these drawbacks, much sound work has been done, and many of the Laboratory students have already obtained excellent posts connected with Astronomy, Telegraphy, Engineering, Sugar-refining, \&c., mainly on account of the training they have received. The good thus done is to be measured, not by the mere fact of the success of these men in life, but by the fact that their success introduces into practical observatories, workshops, \&c., men who have learned the reasons for the manipulations they employ, and who can therefore meet an emergency in ways which no rule-of-thumb teaching could possibly have suggested.

In Anatomy and Chemistry, practical teaching has long been established, and is afforded to every medical student and to such others as study these subjects as parts of a general scientific training. But it is necessary that a great deal more should be done in this direction, especially in the way of affording to advanced students opportunities of cultivating their own powers, and furthering Science by original research. The present arrangements render this possible only to a very limited extent.

Although practical instruction in Physiology, Pathology, and Pharmacology have not formed for so long a period as in Anatomy and Chemistry an integral part of a medical curriculum, yet the University authorities have recognised its importance and have introduced it as far as the meagre space at their disposal would admit. But the increasing demand for a practical training has overcrowded these rooms and made it imperative that additional accommodation should be provided, not only for tuition but for self-training and discovery.

Thus all the practical departments in both the physical and biological sciences urgently demand additional houseroom.

In conclusion, we would again call attention to the fact that one of the great reasons for the present appeal is to be found in the immense success of the University; its mere numerical growth has far exceeded the accommodation provided. But we would also specially note the fact that, although the scheme has just been launched, the contributions already received or promised amount to the very handsome, though of course utterly inadequate, sum of $60,000 l$. At least 40,000 . more, with the equivalent which may reasonably be expected from Government, are recuired to give us yet another University, furnished at least with buildings which will enable it to preserve for another century its well-deserved but hardly-won fame.

But it must not be forgotten that buildings alone, how: ever perfect, are not sufficient for the work desired. The further extension of the teaching staff must inevitably follow. But questions of this nature, as well as the annual supply of funds for the purchase of apparatus and materials, will, we hope, be effectively treated by the Royal Commissiori on Science, whose Report on the Scottish Universities, and whose proposals for their adequate endowment, are, in the North at least, anxiously expected.

\section{SCHORLEMMER'S "CHEMISTRY OF THE CARBON COMPOUNDS"}

A Manual of the Chemistry of the Carbon Compounds; or, Organic Chemistry. By C. Schorlemmer, F.R.S., Lecturer on Organic Chemistry in the Owens College, Manchester. (London: Macmillan and $\mathrm{Co}$, I874.)

UDGING from the rapidity with which text-books on Organic Chemistry have made their appearance of late, it might reasonably be inferred that a good treatise on that subject is much wanted. The student who turns eagerly to the present manual in the hope that the eminent author will help him out of some of his difficulties, and that he will find the subject treated in a novel manner, will however, we fear, feel somewhat disap pointed.

The classification adopted by the author deals first with the compounds of carbon with oxygen, sulphur, and nitrogen; compounds which form the connecting link between inorganic and organic chemistry. He considers, justly, that a knowledge of the compound radicals into which these elements enter is essential to a proper understanding of a large number of other carbon compounds. He then clescribes the large group of fatty substances, subdivided again according to the quantivalence of their radicals, as well as the carbohydrates, terpenes, and camphors. The next division comprises compounds richer in carbon than the fatty substances, and which are not converted into such by the addition of hydrogen. These are again subdivided into several groups, including that of the aromatic compounds, which has been most fully investigated, and the group of compounds containing two or more aromatic nuclei linked together by carbon, and the glucosides. Lastly, we have a division of artificial and natural bases (alkaloids), of colouring and bitter principles, of compounds contained in bile and other secretions of the animal body, and of albumenoids and proteids.

It will be seen from this brief synopsis that the author deviates for the most part from the arrangement which has found favour with many modern writers on Organic Chemistry. Rather than treat of well-defined families of organic bodies, such as hydrocarbons, alcohols, ethers, aldehydes, ketones, acids, \&c., he prefers to retain groups of homologous series, together with their derivatives. To the student this arrangement has the decided drawback that it involves much repetition in examining chemical changes, and, what is niore important, it does not enable him to take in at a glance in what consists the similarity or dissimilarity between classes of bodies of analogous structure, and derived from a homologous parent stock; nor is it so easy to see where one or several links in the various homologous series are miss- 